Survival of Rationalism between Hostility and Economic Growth

Author(s): Süheyla Özyildirim and Nur Bilge Criss

Source: Journal of Peace Research, Vol. 38, No. 4 (Jul., 2001), pp. 515-535

Published by: Sage Publications, Ltd.

Stable URL: https://www.jstor.org/stable/424900

Accessed: 04-02-2019 06:15 UTC

JSTOR is a not-for-profit service that helps scholars, researchers, and students discover, use, and build upon a wide range of content in a trusted digital archive. We use information technology and tools to increase productivity and facilitate new forms of scholarship. For more information about JSTOR, please contact support@jstor.org.

Your use of the JSTOR archive indicates your acceptance of the Terms \& Conditions of Use, available at https://about.jstor.org/terms

Sage Publications, Ltd. is collaborating with JSTOR to digitize, preserve and extend access to Journal of Peace Research 


\title{
Survival of Rationalism Between Hostility and Economic Growth*
}

\author{
SÜHEYLA ÖZYILDIRIM
}

Department of Management, Bilkent University

NUR BILGE CRISS

Department of International Relations, Bilkent University

\begin{abstract}
This article examines the interaction of country pairs who have historically been and are potentially hostile. Hostility is described as a function of arms stocks versus bilateral trade. Armament intensifies the current level of hostility whereas trade reduces the possibility of militarized disputes. We argue that welfare-maximizing decisionmakers have to seek methods other than accumulation of arms to increase the security of their nations, and we highlight the strategic nature of trade in overcoming enmity. Rational governments, who consider bilateral trade as a factor that reduces the level of enmity, allocate resources more efficiently between arms imports and consumer goods. The model predicts that understanding the use of trade as a diplomatic tool will lead the economy to grow significantly. The model is designed as a non-cooperative dynamic game and solved numerically using an adaptive learning algorithm called a genetic algorithm.
\end{abstract}

\section{Introduction}

There is a large literature (see Brito, 1972; Simaan \& Cruz, 1975; Intriligator, 1975; Deger \& Sen, 1983; Garfinkel, 1990; van der Ploeg \& de Zeeuw, 1990; Levine \& Smith, 1997) on the competitive accumulation of weapons between nations dating back (Richardson, 1960) to arms race models. Most of these theoretical analyses employ differential game theory to analyze the intertemporal security/consumption tradeoffs inherent in these models. The models proposed are solved by the assumption that

\footnotetext{
*The authors are grateful to four anonymous referees for their valuable comments and suggestions that have led to significant improvements to the article. We also wish to thank Alper Yilmaz for comments and encouragement.
}

countries act as rational agents concerned with both consumption and the public evil of a war. However, there is a paucity of research incorporating the accumulation of capital besides arms to understand the security/ growth trade-off in a dynamic game setting. ${ }^{1}$ Hence, this article presents a more comprehensive model to examine the long-run growth trajectories of two potentially hostile

${ }^{1}$ Even though many studies investigate the relationship between defense spending and economic performance, dynamic game structure is yet underplayed in the literature. See Deger \& Smith (1983), Faini, Annez \& Taylor (1984), Mintz \& Huang $(1990,1991)$, Ward \& Davis (1992) and Cappelen, Gleditsch \& Bjerkholt (1992) for the trade-off between defense spending and civilian resource use (the guns vs. butter trade-off or the guns vs. investment tradeoff). For other perspectives concerning the relationship between military expenditure and economic growth, see the extensive literature listed in Heo (1998). 
countries who spend their national income on arms imports, consumption, and investment.

Recently, the international relations literature has challenged both theoretically and empirically the trade/conflict relationship by using game-theoretic or expected utility models (Barbieri, 1996; Reuveny \& Kang, 1998; Polachek, Robst \& Chang, 1999; Oneal \& Russett, 1999). Polachek, Robst \& Chang (1999) and Oneal \& Russett (1999) draw attention to contiguity, in that conflict between neighboring countries would be greater than observed if it were not for the mitigating effects of trade. A common argument is that international trade prevents conflict because the possible loss of trade reduces the willingness to fight. Accordingly, in this article, we argue that welfare-maximizing decisionmakers have to seek methods other than accumulation of arms to increase the security of their nations, and we highlight the strategic nature of trade in overcoming enmity. The inability of political leaders in conflictprone countries to capture the benefits of mutual interaction seriously hampers growth.

We measure hostility as the function of arms stocks versus bilateral trade. Armament intensifies the current level of hostility, whereas trade reduces the possibility of militarized disputes. We assume that importers avoid establishing ties with exporters in the adversary country because of the possibility that one government might rupture these ties. Therefore, the decision to accumulate arms influences the existing level of hostility, which has a direct deterrent effect on net bilateral trade and aggregate output.

The welfare of a country depends on the level of consumption and the level of security (which is perceived to be an increasing function of its own weapons stock). Generally, the relative importance of security and consumption on the overall welfare function is described by exogenously determined preference parameters. Here, we endogenize these parameters to explore the indirect effect of hostility on growth. Namely, preferences for security and consumption vary according to the choices made by incumbent governments. If hostility between two nations intensifies, government leaders prefer to invest more in arms since the relative significance of security increases. Thus, we incorporate the rationale for the excessive armament policies of some political leaders whose countries are subject to severe economic constraints.

The interconnection between growth, investment, and military expenditure is necessarily complex. Hence, one of the important innovations of this article is to introduce an adaptive learning algorithm called genetic algorithm to study the dynamics of such complicated models under certain plausible parameters. This stochastic, directed search algorithm is a useful representation of trial-and-error learning that has important advantages over existing solution procedures in complex dynamic games. ${ }^{2}$ The genetic algorithm helps solve a conundrum that has long bedevilled conventional problem-solving methods: striking a balance between exploration and exploitation. Once one finds a good strategy (policy) it is possible to concentrate on exploiting that strategy. Holland (1975: 69), who is the founder of genetic algorithms, argues that

the choice carries a hidden cost because exploitation makes the discovery of truly novel strategies unlikely. Improvements come from trying new, risky things. Because many of the risks fail, exploitation involves a degradation of performance. Deciding to what degree the present should be mortgaged for the future is a classic problem for all systems that adapt and learn.

Walt (1999: 22) argues that 'a logically consistent and mathematically rigorous theory is of little value if it does not illuminate some important aspects of the real

${ }^{2}$ See Smoker (1989) for a discussion of artificial intelligence models of arms races. 
world'. Our model is devised to make longrun predictions for conflicting countries, so we only provide simulation results using genetic algorithms for supportive evidence. We also present a case study of Russia and Turkey and illustrate how mutual interaction, and thus learning, affect political preferences toward efficiency. The case study aims to justify one of the crucial assumptions of the model on the endogenous preference parameters chosen by the policymakers.

\section{The Model}

Consider that there are two potentially hostile countries, $i$ and $j$. The decisionmaker in each country has preferences described by identical lifetime utility functions:

$$
V_{i}=\max \sum_{t=0}^{\infty} \beta^{t} u\left(C_{i t}, A_{i t}\right)
$$

where $C_{i t}$ is consumption of country $i$ at time $t, A_{i t}$ is beginning-of-period arms stock and $\beta$ is the rate of time preference. Given the initial period arms and capital stocks, $A_{i 0}$ and $K_{i 0}$ respectively, the government's objective is to choose optimal (maximizing $u($.$) )$ sequences $\left\{\left(C_{i t}, N_{i t}\right)\right\}_{t=0}^{\infty}$ where $N_{i t}$ is new arms imported at time $t$.

Let $\delta$ be arms depreciation or obsolescence rate; the next period's arms stock, $A_{i t+1}$, is the summation of net of beginning-of-period arms stock and new arms imports. Then

$$
A_{i t+1}=(1-\delta) A_{i t}+N_{i t}
$$

describes the accumulation of arms stocks for country $i$ at period $t$. Neither nation has complete freedom of its consumption and weapon expenditures since total expenditures must not exceed the net national output, $Y_{i t}$. Thus the budget constraint is expressed by the equation

$$
Y_{i t}=C_{i t}+I_{i t}+p N_{i t}+M_{j t}-M_{i t}
$$

where $p$ is the price of imported arms relative to the price of consumer goods, $M_{i t}$ is the imports of consumer goods from conflicting country $j$ and $M_{j t}$ is exports to country $j$ (or imports of $j$ ). $I_{i t}$ represents investment or net increase in the stock of physical capital at point in time, $K_{i t}$ $I_{i t}=K_{i t+1}-K_{i t}$.

Equation (3) is the national income identity, linking aggregate output to aggregate expenditure. We characterize the aggregate output as $Y_{i t}=F\left(K_{i t}\right)$ and define economic growth as the output growth or accumulation of capital over time. By rearranging (3),

$$
\begin{aligned}
& K_{i t+1}-K_{i t}=F\left(K_{i t}\right)- \\
& C_{i t}-p N_{i t}-M_{j t}+M_{i t}
\end{aligned}
$$

we can show that the rate of capital accumulation is affected not only by the home country's arms imports, $N_{i t}$, but also by imports of consumer goods from the opponent country, $M_{i t}$ (bilateral trade).

We assumed that both countries are arms importers, so there is no weapons trade between these conflicting parties; but there could be 'ordinary' trade, so we describe this relation as

$$
M_{i t}=g F\left(K_{i t}\right)-b Z_{j t}
$$

where $Z_{j t}$ measures country $j$ s hostility against $i$. In Equation (4), we argue that countries whose incomes are high may trade more, and the parameter $g \geq 0$ denotes the share of increased import demand from the conflicting country. As emphasized by Pollins (1989), the realized imports between nations could be lower than desired due to existing hostility. He showed that importers take account not only of the price and quality of goods and services but also of the place of origin of these products and of the political relationship between the importing and exporting nations. A common parameter $b \geq$ 0 captures the worsening effect of hostility on 
imports in each country. We specify the hostility in each period for country $i$ and $j$ as

$$
\begin{gathered}
Z_{i t}=\frac{h_{i} A_{j t}^{\theta}}{M_{i t-1}^{\psi_{i}}} \text { and } Z_{j t}=\frac{h_{j} A_{i t}^{\theta}}{M_{j t-1}^{\psi_{j}}} \\
\theta, \psi_{i}, \psi_{j}, h_{i}, h_{j} \geq 0
\end{gathered}
$$

where $h_{i}$ and $h_{j}$ denote the inherent constant hostility parameters of conflicting nations against each other respectively. $Z$ grows by the increase in the rival's beginning-of-period arms stock and decreases by the increase in trade links realized at period $t-1 . \psi_{i}$ and $\psi_{j}$ are exogenous parameters chosen by the social planners to weigh the effect of economic links on hostility. ${ }^{3}$ If $\psi_{i}=0$, this means that the incumbent government in country $i$ ignores trade relations in the calculation of hostility and considers only arms accumulation as the indicator of hostile intentions from the adversary country. If the rulers or politicians have no policy preferences of their own and are conflict averse, then $\psi$ must be different from zero since it is assumed that bilateral trade reduces the tension or hostility between nations, and with that national income (output) increases as well as social welfare. The exponential order of hostility due to arms accumulation is measured by another common parameter, $\theta \geq 0$.

Welfare function is specified as $u\left(C_{i t}, A_{i t}\right)$ $=C_{t}^{1-\gamma_{i}} A_{t}^{\gamma_{i}}$, where the parameters $1-\gamma_{i}$ and $\gamma_{i}$ denote the government's tastes for consumption and arms stock respectively. Arms stock increases the well-being of the citizens through increased security, but there is a trade-off between consumption and the accumulation of arms. Higher weapon stocks eventually increase the feeling of security (Brito, 1972) and thus welfare, but also mean that there are less resources available for consumption, and therefore welfare diminishes. Nonetheless, the distribution of the aggregate

\footnotetext{
${ }^{3}$ In order to capture the positive effect of trade on hostility, the above formulation of $Z$ necessitates $M_{i t}$ and $M_{j t}$ to be greater than 1 for all $t$.
}

output to consumption and arms stock is determined by the preference term, $\gamma_{i}$, chosen by social planners. The taste for armament, $\gamma_{i}$, is specified as follows:

$$
\gamma_{i}=Z_{i t} /\left(\sigma+\mathrm{Z}_{\mathrm{it}}\right)
$$

where $0 \leq \sigma \leq 1$ is any constant parameter to restore diminishing marginal utility, namely, $0 \leq \gamma_{i} \leq 1 .{ }^{4}$ If the hostility index, $Z$, is small due to either less armament of the adversary country or to the strong economic link to that country, the incentive $\gamma=Z /(\sigma+Z)$ to accumulate arms decreases. Therefore the income dedicated to arms imports is transferred to consumption. By endogenizing the preference parameters, we are able to incorporate the effect that armament policies not only increase security but (since they also intensify hostility) lead to further armament over time.

Also, nation $j$ solves a similar problem as follows:

$$
V_{j}=\max \sum_{t=0}^{\infty} \beta^{t} C_{j t}^{1-\gamma_{j}} A_{j t}^{\gamma_{t}}, \quad 0 \leq \gamma_{j} \leq 1
$$

subject to

$$
\begin{gathered}
A_{j t+1}=N_{j t}+(1-\delta) A_{j t}, \\
K_{j t+1}=F\left(K_{j t}\right)+K_{j t}-C_{j t}- \\
p N_{j t}-M_{i t}+M_{j t}, \\
M_{j t}=g F\left(K_{j t}\right)-b Z_{i t} .
\end{gathered}
$$

In the above problem, the initial period values for capital stock, $K_{j 0}$, arms stock, $A_{j 0}$, and home country imports, $M_{j-1}$ are given. ${ }^{5}$

\footnotetext{
${ }^{4}$ Most people are subject to diminishing marginal utility, which means that they gain less and less satisfaction per unit as more and more of something is consumed.

${ }^{5} M_{j-1}$ denotes country $j$ s initial period $(t=-1)$ of import demand of consumption goods from country $i$. We need import demands at time -1 to calculate respective $Z s$ at time 0 .
} 


\section{Case Study: Turkish-Russian Relations}

In the above model, we made a crucial assumption that eradicating hostility and promoting cooperation is an important step leading to peace and economic growth. One method of diminishing hostility and bringing about cooperation is to increase the cost of hostility between conflicting nations (Polachek, 1980). Policymakers should consider diminution of welfare associated with potential trade losses and learn to expand peaceful flows among them - the widening spread of ideas and knowledge, and flows of goods and people in international trade (Kuznets, 1980). In this respect we analyzed Turkish-Russian relations ${ }^{6}$ and presented how centuries-long enmity substantially declined as trade increased. Assumptions that will plausibly turn hostility to healthy competition are as follows:

(1) both countries inherit a strong state tradition, albeit under diverse circumstances. Ad hoc cooperation between echelons of state continue;

(2) although some external circumstances affect mutual misperceptions, confidence-building measures are present;

(3) since the 1998 Russian economic crisis, Turkey has not withheld credit, abrogated agreements, or withdrawn its workforce from Russia;

(4) Turkey and Russia are on a par with each other in their search for political stability, democratization, territorial integrity, and economic growth;

(6) since the demise of the Soviet Union, Turkey's strategic position has become dynamic, freed from NATO's forward

\footnotetext{
${ }^{6}$ Even though there is no Turkish-Russian arms race (as they are incompatible in various ways), this relation deserves to be studied from the perspective that although learning may take a long time, similar goals like democratization, commitment to free market economy, and mutual benefit will decrease antagonism.
}

defense concept. This may be an asset for Russia and Turkey alike, both of whom are facing a Europe reluctant to receive them as part of the political and security architecture; and

(7) opposite stances that Turkey and Russia took regarding conflicts in the Balkans and Nagorno-Karabakh never became an issue in bilateral relations.

In 1964, trade turnover between the Soviet Union and Turkey was minimal, totalling less than $\$ 20$ million. By October 1990 , they agreed to raise the volume of trade to $\$ 4$ billion. By 1991 , for the first time since Stalin revoked the 1925 Treaty of Friendship and Neutrality in 1945, the two countries referred to each other as friends. This positive development was enhanced by membership in the Black Sea Economic Cooperation Organization (initiated by Turkey in 1990 on the assumption that economic interdependence promotes security), and booming trade, projected to reach a volume of $\$ 10$ billion by 2000 .

Meanwhile, political discord on certain issues such as economic rivalry in the Commonwealth of Independent States (CIS), oil transportation issues, Russian attempts to alter the Conventional Forces in Europe (CEF) agreement, playing the Chechen and Kurdistan Worker's Party (PKK) separatism/terrorism respectively against each other strained bilateral relations. As the initial shock of Soviet disintegration began to erode and Turkey's initial enthusiasm to open up to Central Asia and the Caucasus assumed realistic proportions, a balance seems to have been struck in Russian-Turkish relations. The recent trend appears to have overcome points of discord, and mutual economic benefits have begun to dominate.

Declarations, letters of intent, and even protocols aside, Russia became the second largest trade partner of Turkey within a spectacularly short time. Figures from 1995 point 
to stronger Turkish economic ties with Russia than with any other state in the CIS. The trade volume rose to $\$ 3.3$ billion, the value of construction work undertaken by Turkish firms reached $\$ 5.7$ billion, suitcase trade was $\$ 1$ billion, and over one million Russian tourists visited Turkey that year (Babusenko, 1996).

There are three natural gas import projects to/via Turkey: the Azerbaijani pipeline, the Transcaspian pipeline, and the Blue Stream, respectively ranging from the least to the most expensive. The Blue Stream was criticized on various grounds, such as Russia did not have enough natural gas to fill this pipeline and therefore would buy gas cheaply from Turkmenistan and sell it at a higher price to Turkey. The agreement on the Blue Stream project was one gesture from Turkey towards Russia, since there is much at stake for the welfare of both countries not only in economic but also in political terms.

The most tangible cooperation Russia displayed towards Turkey was its refusal to accommodate the PKK leader on its territory after Turkey forced Syria to extradite him in October 1998. Although some factions in the Duma lent support to the Kurdish parliament-in-exile, the Russian government remained true to its pledge in the 1992 Treaty of Friendship and Cooperation to cooperate against terrorism.

\section{Seeking the Optimal Non- cooperative Solution Using Genetic Algorithms}

Our model is an infinite-horizon noncooperative dynamic game between two potentially hostile countries. Traditionally, the optimal strategies or open-loop $\mathrm{Nash}^{7}$ equilibrium in such a game can be approxi-

\footnotetext{
${ }^{7}$ The open-loop Nash equilibrium concept presumes that optimal choices at each point in time are only conditional on the initial state of the model. Open-loop corresponds to the receipt of no information during the play. See Levine \& Smith (1997) for further discussions in the context of arms races.
}

mated by various optimization techniques under some restrictive assumptions on the functional forms (Bașar \& Oldser, 1982). However, in this study, we will use a new optimization technique called the genetic algorithm (GA) to solve the non-cooperative game between nations. Here, we do not expect decisionmakers to derive first-order conditions for the problem described, but rather allow them to communicate and learn the optimal strategies over time. In the context of our model, we use both the optimization and the learning property of the GA to approximate non-cooperative solutions.

GAs operate on a population of candidate solutions to some well-defined problem. Following each iteration of the algorithm, candidate solutions are evaluated for their performance and are assigned a fitness value. Solutions with relatively high fitness values are more likely to remain in the next generation of candidate solutions than are solutions with relatively low fitness values (Grefenstette, 1986). This process captures the notion of survival of the fittest (natural selection). The algorithm then uses the highly fit candidate solutions to breed new candidate solutions, using naturally occurring genetic operations (see Goldberg, 1989; Michalewicz, 1992).

GAs are powerful general-purpose optimization tools in irregular and complex search spaces. A drawback, however, is the lack of any obvious and generally accepted method of dealing with constraint violations. Given that our model is heavily constrained, this difficulty may seem especially troubling. Nonetheless, we successfully incorporate constraints into 'fitness' or utility functions by way of substitutions. First, we rearrange $\left(3^{\prime}\right)$ and substitute armament Equation (2) to derive $C_{i t}$ as

$$
\begin{gathered}
C_{i t}=F\left(K_{i t}\right)-\underbrace{\left(K_{i t+1}-K_{i t}\right)}_{I i t} \\
-p \underbrace{\left(A_{i t+1}-(1-\delta) A_{i t}\right)}_{N_{i t}}-M_{j t}+M_{i t}
\end{gathered}
$$


then we insert import demands described by (4) to yield

$$
\begin{gathered}
C_{i t}=F\left(K_{i t}\right)-\left(K_{i t+1}-K_{i t}\right)-p\left(A_{i t+1}-\right. \\
\left.(1-\delta) A_{i t}\right)-\underbrace{g F\left(K_{j t}\right)+\frac{b h_{i} A_{j t}^{\theta}}{M_{i t-1}^{\psi_{i}}}+}_{M_{j t}} \\
\underbrace{g F\left(K_{i t}\right)-\frac{b h_{j} A_{i t}^{\theta}}{M_{j t-1}^{\psi_{j}}}}_{M_{i t}}
\end{gathered}
$$

which is substituted back to Equation (1) and thus, decisionmakers in country $i$ choose time-paths for $\left\{K_{i t+1}\right\}_{t=0}^{\infty}=K_{i 1}, K_{i 2}, \ldots$ and $\left\{A_{i t+1}\right\}_{t=0}^{\infty}=A_{i 1}, A_{i 2}, \ldots$ to maximize the following fitness function:

$$
\begin{gathered}
V_{i}=\max \sum_{t=0}^{\infty} \beta^{t} u\left(K_{i t+1},\right. \\
K_{i t}, K_{j t}, A_{i t+1}, A_{i t}, \\
\left.A_{j t}, M_{i t-1}, M_{j t-1}\right) .
\end{gathered}
$$

By the optimal choices of next period's state variables, countries indirectly choose their optimal consumption, $C_{i t}$, and volume of arms imports, $N_{i t}$. This function is the performance measure of the chosen strategies given the opponent's policies $\left(K_{j t}, A_{j t}, M_{j t-1}\right)$.

For the sake of practicality, the above 'lifelong' fitness function needs to be truncated for some finite period, $T$, using the methodology described by Mercenier \& Michel (1994). This method proposes time aggregation ${ }^{8}$ which requires that the finite-horizon model

8 The transformation of infinite horizon to finite horizon involves various types of decisions. One concern is the length of the finite planning horizon (the transient path). Errors on the optimal trajectory that will result from this approximation may be reduced by increasing the length of the decision horizon with a resulting boost in computational costs. A suitable choice of dynamic aggregation may significantly reduce the dimension of the numerical optimization for a given level of accuracy, hence allowing enrichment of other aspects of the model (see Mercenier \& Michel, 1994).

9 The steady state or long-run equilibrium can be defined as the state or equilibrium where all the variables grow at a constant (possibly zero) rate. has the same steady state ${ }^{9}$ as the infinitehorizon analog. In the numerical experiment, we will use the above function, $V_{i}$, to evaluate how chosen strategies meet welfare-maximizing objectives of the governments. Initially, we assume that neither country knows the opponent's strategies. Given some random strategies of country $j,\left\{\left(K_{j t}, A_{j t}\right\}_{t=0}^{T}\right.$, and country $i,\left\{\left(K_{i t}, A_{i t}\right\}_{t=0}^{T}\right.$, the success of this initial generation of strategies is tested using each country's relevant fitness functions. The learning process starts after initial generation. From the candidate strategies in the initial generation, the best-performing strategy set is publicized by sending this information to what we call an information exchange center (Figure 1). Through the game, neither country knows the problems of the opponent or the opponent's preferences in their entirety, but has information about relevant strategies against itself. With the availability of this information, countries update the population of latest strategies and send the $u p$-to-date best ${ }^{10}$ strategy set (including capital and arms stock) to the information exchange center at the end of each generation. In the convergence state, none of the players alter strategies against each other. Therefore, the game is over for the planning horizon, and the final strategies would be the equilibrium (optimal) time-paths for investment and arms accumulation. This equilibrium is the GA equilibrium of the game.

In our model, since there are two nations, we run two separate GAs, each to play one side of the game. Each country has its own utility function and population of possible strategies. The utility functions of each player might have different parameters and functional forms depending on the problem described. Based on the complexity of the fitness function, one player might evaluate the performance of its strategies faster than the other player. However, in order to learn

${ }^{10}$ In Figure 1, up-to-date best strategies are denoted by superscript $b$. 
Figure 1. The Evolution of Learning and Optimization Through GA

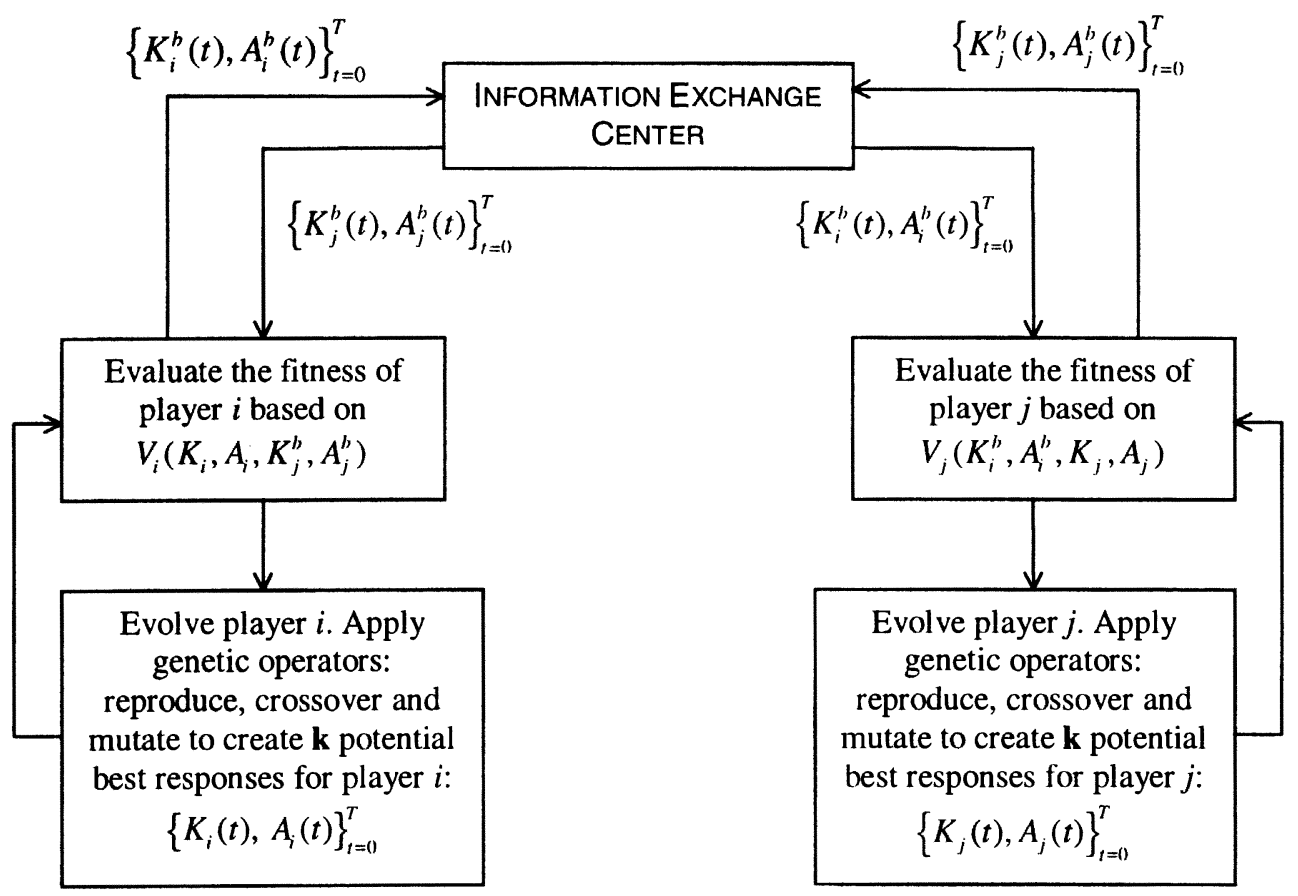

the action of the other player against its strategies, each player waits for the other player's action in each generation. Thus, the game must be played synchronously and genetic operators must be applied sequentially to each generation (Özyıldırım, 1997).

Since the algorithm is a search algorithm, in order to find the equilibrium of the problem we do not need to take derivatives (to derive first-order conditions) but only substitute the best values into the evaluation function. No one expects governments to solve mathematical problems, but their objectives are to maximize overall welfare which require optimization. By our alternative procedure, governments merely write down their objective function and search for optimal strategies by trial-and-error learning algorithm. A number of experimental studies (see Goldberg, 1989; Michalewicz, 1992) have shown that GAs exhibit impressive efficiency in practice. While classical gradient search techniques are more efficient for problems which satisfy tight constraints (for instance, continuity, low dimensionality, uni-modility, etc.), GAs consistently outperform both gradient search techniques and various forms of random search on more difficult (and more common) problems such as optimization involving high dimensionality, multi-modality and non-linearity. The model devised in this study is sufficiently high dimensional and non-linear, so we prefer to introduce this random search algorithm which is not confined to searching locally.

\section{Numerical Experiments}

We simulate the above model under four different cases of political leaders' preferences on the importance of bilateral trade as foundation of peace: (i) $\psi_{i}=\psi_{j}=0$, (ii) $\psi_{i}=\psi_{j}$ $=1.25$, (iii) $\psi_{i}=1.25, \psi_{j}=0$, and (iv) $\psi_{i}=0$, $\psi_{j}=1.25$. The production function is 
Figure 2. Benchmark Case
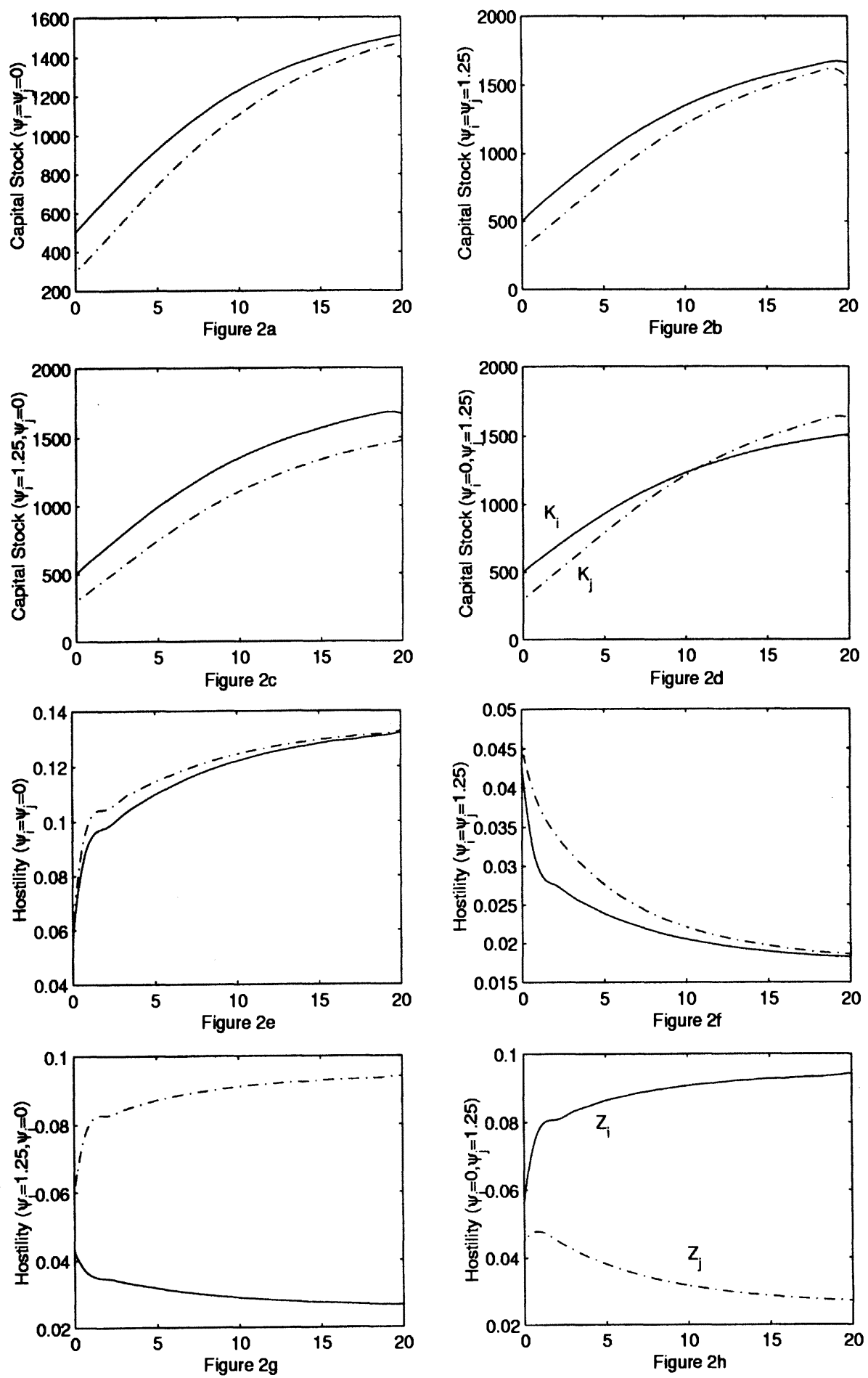
assumed as Cobb-Douglas for both countries: $F(K)=a K^{\alpha}$ and the other parameters ${ }^{11}$ are: $a=1, b=1, \alpha=0.65, h_{i}=h_{j}=0.02, g=$ $0.02, \sigma=0.4, \delta=0.2, \beta=0.95, p=1, \theta=$ $0.25, K_{i 0}=500, K_{j 0}=300, A_{i 0}=5, A_{j 0}=4$, and $M_{i-1}=M_{j-1}=1.25$. In the time aggregated model we assume 20 periods with a dense equally spaced gridding of the time horizon, $T=200$, which is sufficient to capture convergence.

With this parametrization, Figure 2 presents the simulated trajectories of capital stock and hostility for our numerical experiments. Although our model is deterministic, the non-linear structure of the model raises the possibility of multiple equilibria. However, under these parameters, optimal trajectories derived by GA are unique and stationary. GA seeks only the global optimum as the evolutionary equilibrium. The implicit parallelism of GAs ensures that the search is efficient. The central idea behind the parallelism of GAs is that each of the formula elements defines hyperplanes, i.e. subregions of the search space where GA traverses all these subregions to find the best solution.

First, we summarize the main findings in the long run:

- Countries grow more in the long run if they are governed by political leaders who consider trade as a tool to reduce hostility. This result is more evident when the cases $\psi_{i}=\psi_{j}=1.25$ and $\psi_{i}=\psi_{j}=0$ are compared. In the former case, steady state national products are $Y_{i}^{*}=124.03, Y_{j}^{*}=$ 122 (see Figure 2b), whereas in the latter, respective outputs are $Y_{i}^{*}=116.44, Y_{j}^{*}=$ 114.65 (see Figure 2a).

- Countries initially small in terms of physical capital or national product, but ruled by governments that consider trade's positive effect on hostility, grow

11 Some parameter values are used by Levine \& Smith (1997) to simulate the arms race between Greece and Turkey. more and become wealthier than their adversaries (for $\psi_{i}=0, \psi_{j}=1.25$, initial outputs, $Y_{j 0}=40.75, Y_{i 0}=56.80$ become $Y_{j}^{*}=122.57, Y_{i}^{*}=116.44$ in the long run). From Figure 2d, we observe that in country $j$, which initially has less capital stock, $K_{j 0}$ reaches the same level as in $i$ around the tenth aggregated time-period, and grows further thereafter.

- If a country has initially higher national product than its opponent and is ruled by a government that recognizes the importance of bilateral trade in the construction of mutual concord $\left(\psi_{i}=1.25, \psi_{j}=0\right)$, the output gap $\left(Y_{i}^{*}-Y_{j}^{*}\right)$ between these two countries increases further in the long run (see Figure 2c: initial $Y_{*^{0}}=56.80$ and $Y_{j 0}$ $=40.75$ turn into $Y_{i}^{*}=124.39, Y_{j}^{*}=$ 114.65 at the steady state).

- Long-run welfare compositions drastically change in favor of arms accumulation among conflicting countries that are ruled by ignorant governments. When $\psi_{i}=\psi_{j}=$ 0 , initial composition of $C_{i 0}>A_{i 0}\left(C_{j 0}>\right.$ $\left.A_{j 0}\right)$ changes to $C_{i}^{*}<A_{i}^{*}\left(C_{j}^{*}>A_{j}^{*}\right)$ in the long run.

We also present evidence that hostility declines over time if either country has $\psi=$ 0 (see Figures $2 \mathrm{~g}$ and $2 \mathrm{~h}$ ) or both countries have $\psi$ s other than zero (see Figure $2 \mathrm{f}$ ). In the model, we described the preference parameter on security as $\gamma=Z /(Z+\sigma)$; hence, declining patterns of hostility suggest that preference for armament declines over time. From the citizen's point of view, the diminishing desire of governments for armament means that more resources would be allocated to consumer goods (see Table I). Thus, not only more is invested but also the composition of total resources invested favors the consumer goods sector as compared with the military sector. In all cases other than the benchmark case $\psi_{i}=\psi_{j}=0$, arms stock is lower than consumption over the transition paths. In the benchmark case, 
the volume of arms stock increases so fast that after the fourth aggregated time-period, military stocks in each period become higher than consumption. Concomitant with higher capital accumulation and output (Figure 2a), more resources are devoted to the military sector at the expense of necessary goods. ${ }^{12}$

Finally, from Table II, total respective discounted welfare and changes in the defense burden (share of arms imports in national output) over time may be compared.

We observe substantial welfare gains, even when one of the governments in this arms race has less hostile intentions and understands the importance of trade in this process. Also, when we compare the burden of military expenditures at period 0 and steady state, it is apparent that in cases where governments are 'rational' $\left(\psi_{i} \neq 0\right.$ and/or $\psi_{j}$ $\neq 0$ ), they keep the burden at almost the same level or reduce it further. However, governments that ignore trade in their decisions would endure an increasing burden of military expenditures up to $15-20 \%$ of the national output at the steady state.

\section{Sensitivity Analysis}

In order to further assess the robustness of the results reported in the previous section, the basic model has been tested for changes in the focus parameters: exponential impact of trade on hostility, $\psi$, and exponential impact of the arms stock of the adversary on hostility, $\theta$. We have so far confined attention to situations in which either one country totally ignores trade's importance on hostility or both countries give the same weight to the trade effect. Thus, in order to discern the relative sensitivity of the equilibrium paths to the strengths of these effects, we resolve our model for different unequal values of $\psi$ s and

12 This result can be observed in various countries whose citizens have suffered for long periods. A recent case is North Korea. This country is one of the world's poorest and maintains the world's fifth largest army. $\theta$ s. Specifically, we run 12 different simulations for $\psi=\{0,0.25,0.75,1.25\}$ and $\theta=$ $\{0.25,0.35\}$. The optimal trajectories are reported in Tables III and IV (see Appendix). First, we observed that as long as $\psi$ increases, hostility decreases. Hence, by the decline in the motivation of arms accumulation, available resources are distributed more to the physical capital (see Figures 3a and 3e). Thus, countries with more capital grow more in the long run. Second, in the experiments ${ }^{13}$ under different $\theta s$, all else being equal, if arms accumulation is weighted more as the indication of enmity, rivals' armament increases together with growing hostility (see Figures $3 \mathrm{~d}$ and $3 \mathrm{~h}$ ). Hence, countries having higher $\theta$ grow less in the steady state (see Figures $3 c$ and 3g). Finally, in Table III, we show that even for unequal values of $\psi$, the result that excessive growth of an initially capital-poor (but $\psi_{j}>\psi_{i}$ ) country over an initially capitalrich one is robust. Over time, $K_{j 0}<K_{i 0}$ turns to $K_{j}^{*}>K_{i}^{*}$ at the equilibrium.

\section{Conclusion}

This article offers insights into the connection between bilateral trade and politics and the learning process in a dynamic game setting. ${ }^{14}$ It constructs a model in which political leaders are assumed to be utility maximizers who seek to satisfy security as well as economic welfare. Parameters that summarize the relative importance of security and consumption are endogenously determined. The optimal choice of arms import affects the existing level of hostility, which we argue is a crucial decisive factor. The level of enmity is assumed to be positively related to the rival's armament, and inversely related to trade with the rival country.

\footnotetext{
${ }^{13}$ We ran six experiments for $\theta=0.30$, but do not report the (similar) findings due to space limitations.

${ }^{14}$ In this study, we ignored the cooperative game since optimal strategies would not be credible in such complex international problems.
} 
Table I. Optimal Time Paths of Arms Stock and Consumption

\begin{tabular}{rrrrrrrrr}
\hline & \multicolumn{2}{c}{$\psi_{i}=0$} & \multicolumn{2}{c}{$\psi_{i}=1.25$} & \multicolumn{2}{c}{$\psi_{i}=1.25$} & \multicolumn{2}{c}{$\psi_{i}=0$} \\
\hline$t$ & \multicolumn{1}{c}{$A_{i}$} & \multicolumn{1}{c}{$C_{i}$} & \multicolumn{1}{c}{$A_{i}$} & \multicolumn{1}{c}{$C_{i}$} & \multicolumn{1}{c}{$A_{i}$} & \multicolumn{1}{c}{$C_{i}$} & \multicolumn{1}{c}{$A_{i}$} & \multicolumn{1}{c}{$C_{i}$} \\
\hline 0 & 5.00 & 43.29 & 5.00 & 43.60 & 5.00 & 43.64 & 5.00 & 43.34 \\
1 & 39.13 & 45.51 & 14.03 & 51.49 & 16.56 & 50.74 & 34.26 & 46.94 \\
2 & 46.32 & 50.45 & 15.01 & 58.37 & 18.12 & 57.52 & 39.71 & 52.21 \\
3 & 53.52 & 55.10 & 15.98 & 64.89 & 19.67 & 63.80 & 45.16 & 57.23 \\
4 & 60.52 & 59.47 & 16.95 & 71.07 & 21.04 & 69.95 & 50.22 & 61.97 \\
5 & 67.14 & 63.27 & 17.53 & 76.60 & 22.40 & 75.57 & 55.08 & 66.12 \\
6 & 73.17 & 66.92 & 18.12 & 82.02 & 23.57 & 80.74 & 59.36 & 70.11 \\
7 & 79.00 & 70.20 & 18.70 & 86.78 & 24.54 & 85.49 & 63.44 & 73.73 \\
8 & 84.26 & 73.02 & 19.09 & 91.15 & 25.32 & 90.00 & 67.14 & 77.01 \\
9 & 89.12 & 75.77 & 19.48 & 95.13 & 26.09 & 93.88 & 70.45 & 80.00 \\
10 & 93.59 & 78.22 & 19.87 & 98.76 & 26.87 & 97.43 & 73.36 & 82.52 \\
11 & 97.68 & 80.27 & 20.06 & 101.89 & 27.46 & 100.51 & 76.09 & 84.84 \\
12 & 101.18 & 82.14 & 20.45 & 104.91 & 27.84 & 103.48 & 78.42 & 86.95 \\
13 & 104.49 & 83.84 & 20.65 & 107.48 & 28.43 & 106.00 & 80.56 & 88.70 \\
14 & 107.21 & 85.18 & 20.84 & 109.81 & 28.62 & 108.15 & 82.51 & 90.47 \\
15 & 110.13 & 86.44 & 21.04 & 111.91 & 29.01 & 110.12 & 84.26 & 91.90 \\
16 & 112.07 & 87.48 & 21.04 & 113.50 & 29.40 & 111.95 & 85.62 & 93.20 \\
17 & 114.02 & 88.59 & 21.23 & 115.01 & 29.60 & 113.65 & 87.17 & 94.37 \\
18 & 115.96 & 89.43 & 21.23 & 116.41 & 29.79 & 115.02 & 88.15 & 95.28 \\
19 & 117.52 & 90.32 & 21.62 & 120.94 & 30.18 & 119.66 & 89.31 & 95.96 \\
20 & 121.22 & 92.16 & 21.81 & 119.62 & 30.76 & 118.08 & 91.84 & 98.15 \\
\hline
\end{tabular}

\begin{tabular}{rrrrrrrrrr}
\hline & \multicolumn{2}{c}{$\psi_{j}=0$} & \multicolumn{2}{c}{$\psi_{j}=1.25$} & \multicolumn{2}{c}{$\psi_{j}=1.25$} & \multicolumn{2}{c}{$\psi_{j}=0$} \\
\hline$t$ & \multicolumn{1}{c}{$A_{j}$} & $C_{j}$ & \multicolumn{1}{c}{$A_{j}$} & \multicolumn{1}{c}{$C_{j}$} & $A_{j}$ & \multicolumn{1}{c}{$C_{j}$} & \multicolumn{1}{c}{$A_{j}$} & $C_{j}$ \\
\hline 0 & 4.00 & 29.03 & 4.00 & 29.34 & 4.00 & 29.15 & 4.00 & 29.40 \\
1 & 28.43 & 32.86 & 12.09 & 36.95 & 23.95 & 34.19 & 14.81 & 36.10 \\
2 & 35.43 & 38.42 & 13.26 & 44.08 & 29.21 & 39.90 & 16.56 & 43.11 \\
3 & 42.63 & 43.50 & 14.42 & 50.98 & 34.65 & 45.62 & 18.51 & 49.90 \\
4 & 49.83 & 48.60 & 15.59 & 57.67 & 40.10 & 51.04 & 20.06 & 56.47 \\
5 & 56.63 & 53.09 & 16.37 & 64.12 & 45.35 & 56.02 & 21.62 & 62.81 \\
6 & 63.25 & 57.76 & 17.15 & 70.28 & 50.22 & 60.79 & 22.79 & 68.89 \\
7 & 69.86 & 61.73 & 17.92 & 76.11 & 54.88 & 65.14 & 23.95 & 74.48 \\
8 & 75.89 & 65.56 & 18.51 & 81.27 & 59.16 & 69.28 & 24.93 & 79.65 \\
9 & 81.34 & 68.83 & 18.90 & 86.22 & 63.25 & 72.83 & 25.70 & 84.61 \\
10 & 86.40 & 71.81 & 19.29 & 90.70 & 66.94 & 76.25 & 26.48 & 89.11 \\
11 & 91.07 & 74.54 & 19.67 & 94.58 & 70.25 & 79.16 & 27.07 & 93.03 \\
12 & 95.35 & 77.05 & 20.06 & 98.33 & 73.17 & 81.81 & 27.65 & 96.80 \\
13 & 98.85 & 79.34 & 20.26 & 101.54 & 75.89 & 84.06 & 28.23 & 100.02 \\
14 & 102.35 & 81.35 & 20.45 & 104.30 & 78.03 & 86.17 & 28.62 & 102.98 \\
15 & 105.65 & 82.97 & 20.65 & 107.03 & 80.17 & 88.24 & 29.01 & 105.68 \\
16 & 108.57 & 84.58 & 20.84 & 109.31 & 82.31 & 89.93 & 29.21 & 107.77 \\
17 & 110.13 & 85.84 & 21.04 & 111.43 & 83.87 & 91.50 & 29.60 & 109.93 \\
18 & 113.05 & 87.27 & 21.04 & 113.36 & 85.42 & 92.73 & 29.79 & 111.74 \\
19 & 115.19 & 87.96 & 21.43 & 124.74 & 86.79 & 93.85 & 30.18 & 116.89 \\
20 & 119.66 & 90.76 & 21.81 & 114.24 & 90.29 & 96.75 & 30.96 & 116.31 \\
\hline
\end{tabular}

These transition paths are derived after averaging results of ten experiments which are run with different initial random starting points. In a typical run we use a population size of 50 , crossover rate of 0.60 and mutation rate of 0.01 . 
Table II. Total Discounted Welfare and Defense Burden

\begin{tabular}{lccccccc}
\hline \multicolumn{3}{c}{ Country $i$} \\
\hline$\psi_{i}$ & $\psi_{j}$ & $V_{i}$ & $p N_{i}(0) / Y_{i}(0)$ & $p N_{i}^{*} / Y_{i}^{*}$ & $V j$ & $p N j(0) / Y j(0)$ & $p N_{i}^{*} / Y_{i}^{*}$ \\
\hline 0 & 0 & 4.9839 & 0.0777 & 0.2082 & 4.5970 & 0.0796 & 0.2087 \\
1.25 & 1.25 & 5.0814 & 0.0335 & 0.0352 & 4.6835 & 0.0395 & 0.0368 \\
1.25 & 0 & 5.0651 & 0.0380 & 0.0495 & 4.6012 & 0.0686 & 0.1575 \\
0 & 1.25 & 4.9873 & 0.0691 & 0.1578 & 4.6636 & 0.0462 & 0.0505 \\
\hline
\end{tabular}

Steady-state values are denoted by an asterisk. $V_{i}$ and $V_{j}$ denote respective discounted welfare.

We introduce an adaptive learning algorithm to study the dynamics of such complicated models under plausible parameters. Our analysis concentrates on cases in which, during a hostile peace period, rational governments that recognize the importance of bilateral trade in the construction of mutual concord would surpass their rivals. We show that divergence in initial capital stocks and attitudes of governments to hostility makes substantial differences in the steady-state growth figures. Countries with especially poor resources will benefit more if they are ruled by governments that are 'rational' in the sense that trade is viewed as a diplomatic tool.

The case study of Turkey and Russia explains the importance of trade as a diplomatic tool in constructing peace in regional conflicts. In the existing literature on trade and conflict, various studies (see Hirschman, 1980; Gasiorowski \& Polachek, 1982; Liberman, 1996) illustrate that the manipulation of issues such as trade to gain cooperation from other conflicting players are mostly initiated by the policymakers of developed and democratic countries. In this sense, our example is unique since it illustrates the diplomatic property of interdependence between two 'emerging' economies that have had a long state tradition as well as historical enmity.

The model and the numerical results are useful in understanding the importance of policymakers' rationality in the construction of peace. Conflicting country pairings like Eritrea-Ethiopia, Greece-Turkey, IndiaPakistan, Iran-Iraq, and North-South Korea are mostly subject to severe economic constraints but are still spending substantial amounts on arms imports (Levine $\&$ Smith, 1997). Our model suggests to the policymakers in those conflicting countries that international conflict can be eased considerably by engaging a hostile nation in trade.

Obviously, there are many ways in which the model can be extended. Only a few will be suggested below. The natural extension is to solve the model for closed-loop or feedback Nash equilibrium; this might be of interest for its value-added realism. This type of equilibrium allows each country to condition its strategies on the current and past states. Thus, the feedback model employs a more realistic information pattern. This would, however, require an altogether new genetic game algorithm or the use of another approximation algorithm by simplifying the original structure. Otherwise, the model in this article is already complex enough to find feedback equilibrium of the game with the existing solution techniques in the literature.

The model can be extended to allow stochastic shocks. For example, suppose hostility varies due to political shocks. Changing governments may affect the existing level of hostility, and these changes can be 
Figure 3. Sensitivity Analysis
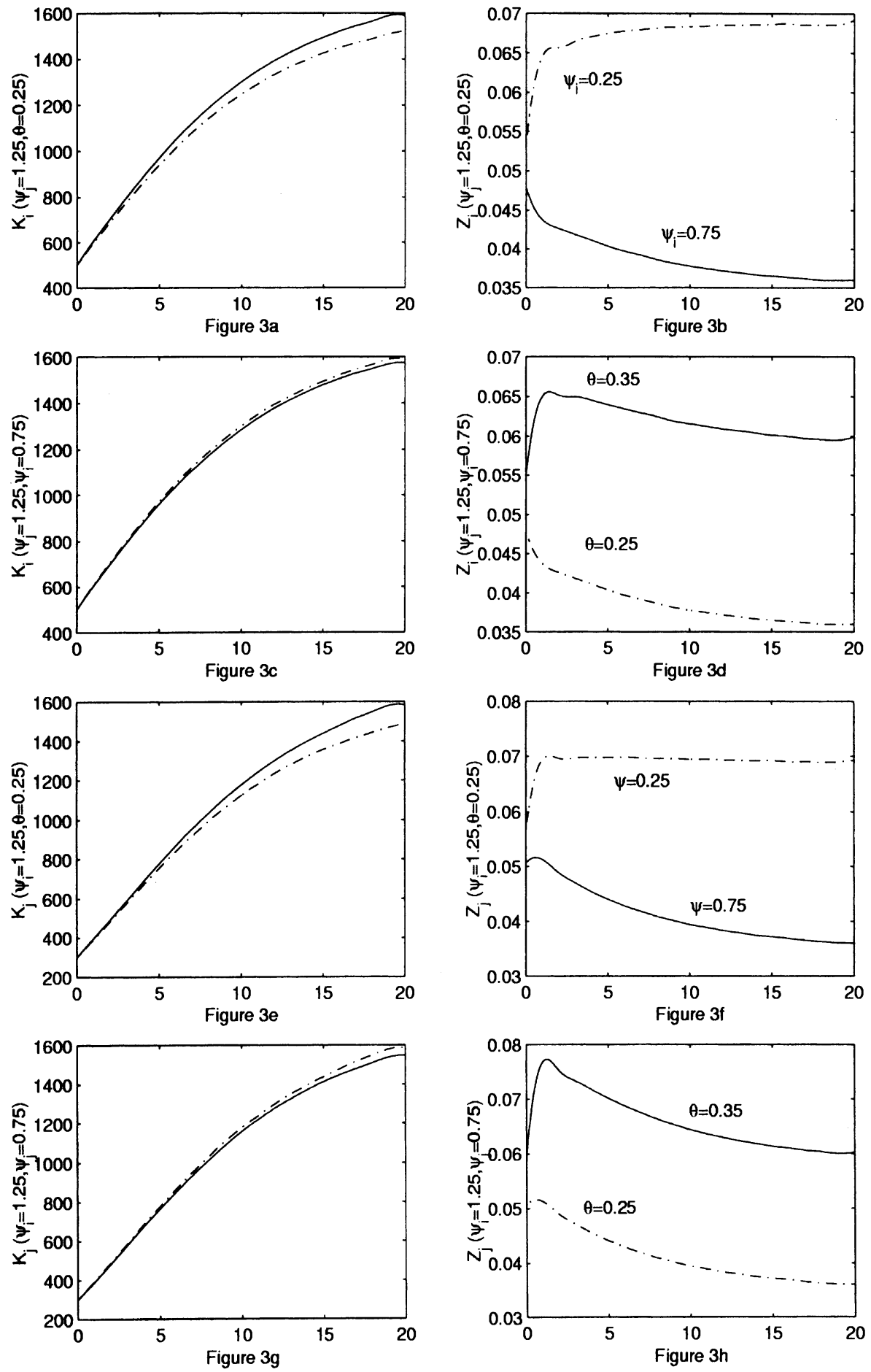
periodically captured by stochastic shocks. hostile nations. However, definition of The price of imported arms and preferences growth in real life is more complex than in can also be subject to shocks. modeling. Although these extensions are

One empirical study implication of the beyond the scope of this article, they illusmodel is that growth rate of the economy trate the broad range of questions that could reacts in an asymmetric way to hostility. The be addressed based on variations of the model relation can be testable among historically developed here. 


\section{Appendix}

Table IIIa. Optimal Trajectories for Country i $\left(\psi_{j}=1.25\right)$

\begin{tabular}{rrrrrrrrrrr}
\hline & \multicolumn{3}{c}{$\psi_{i}=0, \theta=0.25$} & \multicolumn{3}{c}{$\psi_{i}=0.25, \theta=0.25$} & \multicolumn{2}{c}{$\psi_{i}=0.75, \theta=0.25$} \\
\hline$t$ & \multicolumn{1}{c}{$K_{i}$} & \multicolumn{1}{c}{$A_{i}$} & \multicolumn{1}{c}{$Z_{i}$} & \multicolumn{1}{c}{$K_{i}$} & \multicolumn{1}{c}{$A_{i}$} & \multicolumn{1}{c}{$Z_{i}$} & \multicolumn{1}{c}{$K_{i}$} & \multicolumn{1}{c}{$A_{i}$} & $Z_{i}$ \\
\hline 0 & 500.00 & 5.00 & 0.0566 & 500.00 & 5.00 & 0.0535 & 500.00 & 5.00 & 0.0479 \\
1 & 595.31 & 34.26 & 0.0785 & 598.24 & 29.01 & 0.0646 & 607.04 & 20.26 & 0.0437 \\
2 & 684.75 & 40.10 & 0.0812 & 689.15 & 33.29 & 0.0656 & 703.81 & 22.59 & 0.0426 \\
3 & 771.26 & 45.35 & 0.0834 & 777.13 & 37.38 & 0.0664 & 797.65 & 24.73 & 0.0419 \\
4 & 853.37 & 50.60 & 0.0853 & 860.70 & 41.27 & 0.0670 & 887.10 & 26.87 & 0.0411 \\
5 & 931.09 & 55.27 & 0.0866 & 939.88 & 44.77 & 0.0674 & 970.67 & 28.43 & 0.0403 \\
6 & 1002.93 & 59.75 & 0.0879 & 1013.20 & 47.88 & 0.0677 & 1049.85 & 29.98 & 0.0397 \\
7 & 1068.91 & 63.83 & 0.0888 & 1080.65 & 50.80 & 0.0679 & 1121.70 & 31.54 & 0.0392 \\
8 & 1129.03 & 67.53 & 0.0897 & 1142.23 & 53.52 & 0.0682 & 1187.68 & 32.71 & 0.0386 \\
9 & 1183.28 & 70.83 & 0.0906 & 1197.95 & 56.05 & 0.0683 & 1247.80 & 33.68 & 0.0382 \\
10 & 1233.14 & 73.75 & 0.0912 & 1247.80 & 58.00 & 0.0683 & 1302.05 & 34.65 & 0.0378 \\
11 & 1277.13 & 76.67 & 0.0917 & 1293.26 & 59.94 & 0.0684 & 1350.44 & 35.63 & 0.0375 \\
12 & 1316.72 & 79.00 & 0.0922 & 1332.84 & 61.69 & 0.0685 & 1392.96 & 36.40 & 0.0372 \\
13 & 1351.91 & 81.14 & 0.0925 & 1368.04 & 63.25 & 0.0685 & 1431.09 & 36.99 & 0.0370 \\
14 & 1382.70 & 83.09 & 0.0930 & 1398.83 & 64.42 & 0.0686 & 1464.81 & 37.57 & 0.0367 \\
15 & 1410.56 & 84.84 & 0.0933 & 1426.69 & 65.78 & 0.0686 & 1494.13 & 38.15 & 0.0365 \\
16 & 1434.02 & 86.59 & 0.0936 & 1450.15 & 66.94 & 0.0687 & 1521.99 & 38.54 & 0.0364 \\
17 & 1454.55 & 87.76 & 0.0939 & 1470.67 & 67.33 & 0.0686 & 1545.45 & 38.93 & 0.0362 \\
18 & 1472.14 & 88.73 & 0.0939 & 1488.27 & 68.11 & 0.0686 & 1565.98 & 39.13 & 0.0360 \\
19 & 1491.20 & 89.51 & 0.0939 & 1508.80 & 68.70 & 0.0686 & 1589.44 & 39.52 & 0.0360 \\
20 & 1505.87 & 92.43 & 0.0949 & 1521.99 & 70.83 & 0.0692 & 1589.44 & 40.49 & 0.0360 \\
\hline
\end{tabular}

\begin{tabular}{rrrrrrrrrrr}
\hline & \multicolumn{3}{c}{$\psi_{i}=0, \theta=0.35$} & \multicolumn{3}{c}{$\psi_{i}=0.25, \theta=0.35$} & \multicolumn{2}{c}{$\psi_{i}=0.75, \theta=0.35$} \\
\hline$t$ & \multicolumn{1}{c}{$K_{i}$} & \multicolumn{1}{c}{$A_{i}$} & \multicolumn{1}{c}{$Z_{i}$} & \multicolumn{1}{c}{$K_{i}$} & \multicolumn{1}{c}{$A_{i}$} & \multicolumn{1}{c}{$Z_{i}$} & \multicolumn{1}{c}{$K_{i}$} & \multicolumn{1}{c}{$A_{i}$} & $Z_{i}$ \\
\hline 0 & 500.00 & 5.00 & 0.0650 & 500.00 & 5.00 & 0.0615 & 500.00 & 5.00 & 0.0550 \\
1 & 587.98 & 48.08 & 0.1187 & 592.38 & 41.07 & 0.0973 & 602.64 & 29.01 & 0.0650 \\
2 & 675.95 & 57.41 & 0.1269 & 681.82 & 48.27 & 0.1018 & 697.95 & 33.10 & 0.0651 \\
3 & 762.46 & 65.78 & 0.1324 & 768.33 & 54.88 & 0.1049 & 790.32 & 36.79 & 0.0649 \\
4 & 844.57 & 74.14 & 0.1373 & 850.44 & 61.11 & 0.1072 & 878.30 & 40.10 & 0.0645 \\
5 & 922.29 & 81.73 & 0.1410 & 928.15 & 66.75 & 0.1089 & 960.41 & 43.02 & 0.0639 \\
6 & 994.13 & 88.93 & 0.1446 & 1000.00 & 72.20 & 0.1105 & 1036.66 & 45.74 & 0.0634 \\
7 & 1060.12 & 95.73 & 0.1476 & 1065.98 & 77.06 & 0.1116 & 1107.04 & 48.08 & 0.0629 \\
8 & 1120.23 & 101.76 & 0.1499 & 1126.10 & 81.34 & 0.1125 & 1171.55 & 50.22 & 0.0625 \\
9 & 1174.49 & 107.21 & 0.1520 & 1180.35 & 85.42 & 0.1134 & 1231.67 & 51.97 & 0.0619 \\
10 & 1222.87 & 112.27 & 0.1538 & 1228.74 & 88.73 & 0.1140 & 1285.92 & 53.72 & 0.0616 \\
11 & 1265.40 & 116.74 & 0.1554 & 1272.73 & 92.04 & 0.1148 & 1334.31 & 55.27 & 0.0612 \\
12 & 1303.52 & 120.63 & 0.1567 & 1313.78 & 94.76 & 0.1152 & 1376.83 & 56.63 & 0.0609 \\
13 & 1335.78 & 124.13 & 0.1580 & 1348.97 & 97.48 & 0.1156 & 1414.96 & 57.80 & 0.0607 \\
14 & 1365.10 & 127.05 & 0.1590 & 1379.77 & 99.82 & 0.1159 & 1448.68 & 58.77 & 0.0604 \\
15 & 1391.50 & 129.39 & 0.1596 & 1406.16 & 101.76 & 0.1165 & 1479.47 & 59.55 & 0.0601 \\
16 & 1413.49 & 131.92 & 0.1603 & 1428.15 & 103.52 & 0.1165 & 1505.87 & 60.52 & 0.0600 \\
17 & 1431.09 & 134.44 & 0.1609 & 1448.68 & 104.88 & 0.1165 & 1529.33 & 61.11 & 0.0597 \\
18 & 1445.75 & 135.42 & 0.1615 & 1467.74 & 106.04 & 0.1168 & 1548.39 & 61.50 & 0.0596 \\
19 & 1467.74 & 136.00 & 0.1615 & 1485.34 & 106.82 & 0.1168 & 1568.91 & 62.28 & 0.0596 \\
20 & 1485.34 & 142.03 & 0.1647 & 1501.47 & 110.52 & 0.1183 & 1574.78 & 64.03 & 0.0600 \\
\hline
\end{tabular}

In the comparative statistics with respect to underlying parameters, we kept one country's $\psi$ constant and analyzed the effects of the changes on the other country's trajectories. 
Table IIIb. Optimal Trajectories for Country $j\left(\psi_{j}=1.25\right)$

\begin{tabular}{rrrrrrrrrrr}
\hline & \multicolumn{3}{c}{$\psi_{i}=0, \theta=0.25$} & \multicolumn{3}{c}{$\psi_{i}=0.25, \theta=0.25$} & \multicolumn{2}{c}{$\psi_{i}=0.75, \theta=0.25$} \\
\hline$t$ & \multicolumn{1}{c}{$K_{j}$} & \multicolumn{1}{c}{$A_{j}$} & $Z_{j}$ & \multicolumn{1}{c}{$K_{j}$} & \multicolumn{1}{c}{$A_{j}$} & \multicolumn{1}{c}{$Z_{j}$} & $K_{j}$ & $A_{j}$ & $Z_{j}$ \\
\hline 0 & 300.00 & 4.00 & 0.0453 & 300.00 & 4.00 & 0.0453 & 300.00 & 4.00 & 0.0453 \\
1 & 394.72 & 14.81 & 0.0478 & 396.38 & 14.23 & 0.0457 & 396.38 & 13.06 & 0.0417 \\
2 & 492.77 & 16.95 & 0.0453 & 494.43 & 16.17 & 0.0427 & 494.43 & 14.62 & 0.0383 \\
3 & 594.13 & 18.90 & 0.0425 & 595.80 & 17.92 & 0.0400 & 595.80 & 16.17 & 0.0356 \\
4 & 695.50 & 20.65 & 0.0401 & 697.17 & 19.48 & 0.0377 & 697.17 & 17.53 & 0.0334 \\
5 & 793.55 & 22.01 & 0.0380 & 795.21 & 20.84 & 0.0357 & 795.21 & 18.51 & 0.0314 \\
6 & 889.93 & 23.37 & 0.0363 & 889.93 & 22.01 & 0.0340 & 889.93 & 19.48 & 0.0298 \\
7 & 981.33 & 24.34 & 0.0348 & 979.67 & 22.98 & 0.0326 & 979.67 & 20.45 & 0.0285 \\
8 & 1067.74 & 25.32 & 0.0336 & 1064.42 & 23.95 & 0.0314 & 1064.42 & 21.04 & 0.0274 \\
9 & 1147.51 & 26.29 & 0.0325 & 1144.18 & 24.73 & 0.0304 & 1142.52 & 21.62 & 0.0264 \\
10 & 1222.29 & 27.07 & 0.0315 & 1217.30 & 25.32 & 0.0295 & 1213.98 & 22.20 & 0.0256 \\
11 & 1288.76 & 27.65 & 0.0307 & 1283.77 & 25.90 & 0.0287 & 1278.79 & 22.79 & 0.0249 \\
12 & 1351.91 & 28.23 & 0.0301 & 1346.92 & 26.48 & 0.0281 & 1338.61 & 23.18 & 0.0243 \\
13 & 1408.41 & 28.62 & 0.0295 & 1401.76 & 26.87 & 0.0275 & 1391.79 & 23.57 & 0.0238 \\
14 & 1459.92 & 29.21 & 0.0290 & 1449.95 & 27.26 & 0.0270 & 1439.98 & 23.76 & 0.0234 \\
15 & 1504.79 & 29.60 & 0.0285 & 1493.16 & 27.65 & 0.0266 & 1481.52 & 24.15 & 0.0230 \\
16 & 1548.00 & 29.98 & 0.0282 & 1531.38 & 28.04 & 0.0263 & 1519.75 & 24.34 & 0.0227 \\
17 & 1584.56 & 30.37 & 0.0278 & 1566.28 & 28.04 & 0.0259 & 1554.64 & 24.54 & 0.0224 \\
18 & 1617.79 & 30.37 & 0.0275 & 1596.19 & 28.23 & 0.0257 & 1584.56 & 24.54 & 0.0222 \\
19 & 1649.36 & 30.37 & 0.0272 & 1627.76 & 28.43 & 0.0254 & 1614.47 & 24.93 & 0.0220 \\
20 & 1644.38 & 31.74 & 0.0271 & 1626.10 & 29.60 & 0.0253 & 1612.81 & 25.51 & 0.0219 \\
\hline
\end{tabular}

$\psi_{i}=0, \theta=0.35$

$\psi_{i}=0.25, \theta=0.35$

$\psi_{i}=0.75, \theta=0.35$

\begin{tabular}{rccccccccc}
\hline$t$ & \multicolumn{1}{c}{$K_{j}$} & \multicolumn{1}{c}{$A_{j}$} & $Z_{j}$ & \multicolumn{1}{c}{$K_{j}$} & $A_{j}$ & $Z_{j}$ & $K_{j}$ & $A_{j}$ & $Z_{j}$ \\
\hline 0 & 300.00 & 4.00 & 0.0532 & 300.00 & 4.00 & 0.0532 & 300.00 & 4.00 & 0.0532 \\
1 & 389.74 & 22.40 & 0.0771 & 391.40 & 21.43 & 0.0728 & 393.06 & 19.29 & 0.0641 \\
2 & 484.46 & 27.07 & 0.0767 & 487.78 & 25.32 & 0.0710 & 491.10 & 22.20 & 0.0608 \\
3 & 582.50 & 30.57 & 0.0734 & 587.49 & 28.62 & 0.0676 & 590.81 & 24.93 & 0.0573 \\
4 & 682.21 & 33.87 & 0.0705 & 687.19 & 31.54 & 0.0646 & 690.52 & 27.26 & 0.0543 \\
5 & 780.25 & 36.60 & 0.0677 & 785.24 & 34.07 & 0.0618 & 788.56 & 29.21 & 0.0517 \\
6 & 873.31 & 39.32 & 0.0652 & 879.96 & 36.40 & 0.0594 & 883.28 & 30.96 & 0.0494 \\
7 & 963.05 & 41.66 & 0.0632 & 969.70 & 38.35 & 0.0574 & 973.02 & 32.51 & 0.0474 \\
8 & 1047.80 & 43.60 & 0.0613 & 1054.45 & 40.10 & 0.0555 & 1057.77 & 33.87 & 0.0458 \\
9 & 1125.90 & 45.35 & 0.0597 & 1132.55 & 41.66 & 0.0540 & 1139.20 & 34.85 & 0.0443 \\
10 & 1200.68 & 46.91 & 0.0583 & 1204.01 & 43.02 & 0.0526 & 1213.98 & 36.01 & 0.0430 \\
11 & 1267.16 & 48.27 & 0.0571 & 1268.82 & 44.38 & 0.0515 & 1283.77 & 36.99 & 0.0420 \\
12 & 1330.30 & 49.44 & 0.0560 & 1326.98 & 45.35 & 0.0505 & 1343.60 & 37.77 & 0.0410 \\
13 & 1385.14 & 50.60 & 0.0550 & 1380.16 & 46.32 & 0.0498 & 1396.77 & 38.54 & 0.0402 \\
14 & 1436.66 & 51.58 & 0.0542 & 1426.69 & 47.10 & 0.0491 & 1444.97 & 39.13 & 0.0396 \\
15 & 1481.52 & 52.16 & 0.0534 & 1468.23 & 48.08 & 0.0485 & 1488.17 & 39.52 & 0.0390 \\
16 & 1523.07 & 52.74 & 0.0528 & 1506.45 & 48.46 & 0.0479 & 1528.05 & 40.10 & 0.0386 \\
17 & 1562.95 & 53.33 & 0.0523 & 1539.69 & 48.66 & 0.0474 & 1562.95 & 40.29 & 0.0381 \\
18 & 1602.83 & 53.91 & 0.0516 & 1572.92 & 49.24 & 0.0470 & 1594.53 & 40.68 & 0.0377 \\
19 & 1634.41 & 53.91 & 0.0510 & 1609.48 & 49.44 & 0.0466 & 1627.76 & 41.07 & 0.0374 \\
20 & 1632.75 & 57.02 & 0.0511 & 1607.82 & 51.58 & 0.0465 & 1624.44 & 42.43 & 0.0373 \\
\hline
\end{tabular}


Table IVa. Optimal Trajectories for Country $i\left(\psi_{i}=1.25\right)$

\begin{tabular}{rrrrrrrrrrr}
\hline & \multicolumn{3}{c}{$\psi_{j}=0, \theta=0.25$} & \multicolumn{3}{c}{$\psi_{j}=0.25, \theta=0.25$} & \multicolumn{2}{c}{$\psi_{j}=0.75, \theta=0.25$} \\
\hline$t$ & \multicolumn{1}{c}{$K_{i}$} & $A_{i}$ & $Z_{i}$ & \multicolumn{1}{c}{$K_{i}$} & \multicolumn{1}{c}{$A_{i}$} & $Z_{i}$ & $K_{i}$ & $A_{i}$ & $Z_{i}$ \\
\hline 0 & 500.00 & 5.00 & 0.0428 & 500.00 & 5.00 & 0.0428 & 500.00 & 5.00 & 0.0428 \\
1 & 611.44 & 16.56 & 0.0355 & 611.44 & 15.98 & 0.0343 & 611.44 & 15.01 & 0.0319 \\
2 & 712.61 & 18.31 & 0.0345 & 712.61 & 17.73 & 0.0330 & 712.61 & 16.37 & 0.0302 \\
3 & 810.85 & 20.06 & 0.0334 & 812.32 & 19.09 & 0.0319 & 810.85 & 17.53 & 0.0290 \\
4 & 906.16 & 21.43 & 0.0325 & 907.62 & 20.45 & 0.0309 & 906.16 & 18.51 & 0.0278 \\
5 & 995.60 & 22.79 & 0.0317 & 997.07 & 21.62 & 0.0300 & 995.60 & 19.48 & 0.0268 \\
6 & 1079.18 & 23.95 & 0.0310 & 1080.65 & 22.79 & 0.0292 & 1079.18 & 20.26 & 0.0260 \\
7 & 1156.89 & 24.93 & 0.0303 & 1158.36 & 23.57 & 0.0285 & 1156.89 & 21.04 & 0.0252 \\
8 & 1230.21 & 25.70 & 0.0297 & 1230.21 & 24.34 & 0.0279 & 1228.74 & 21.62 & 0.0246 \\
9 & 1296.19 & 26.68 & 0.0292 & 1294.72 & 25.12 & 0.0274 & 1293.26 & 22.20 & 0.0241 \\
10 & 1354.84 & 27.26 & 0.0288 & 1353.37 & 25.70 & 0.0270 & 1351.91 & 22.59 & 0.0236 \\
11 & 1407.62 & 27.84 & 0.0284 & 1406.16 & 26.29 & 0.0266 & 1404.69 & 23.18 & 0.0232 \\
12 & 1454.55 & 28.43 & 0.0281 & 1453.08 & 26.68 & 0.0263 & 1451.61 & 23.37 & 0.0228 \\
13 & 1497.07 & 29.01 & 0.0278 & 1495.60 & 27.07 & 0.0260 & 1494.13 & 23.76 & 0.0225 \\
14 & 1535.19 & 29.40 & 0.0276 & 1533.72 & 27.46 & 0.0257 & 1532.26 & 23.95 & 0.0223 \\
15 & 1567.45 & 29.60 & 0.0274 & 1567.45 & 27.84 & 0.0255 & 1565.98 & 24.34 & 0.0221 \\
16 & 1596.77 & 29.98 & 0.0272 & 1598.24 & 27.84 & 0.0253 & 1595.31 & 24.54 & 0.0219 \\
17 & 1626.10 & 30.18 & 0.0270 & 1624.63 & 28.23 & 0.0251 & 1621.70 & 24.54 & 0.0217 \\
18 & 1651.03 & 30.37 & 0.0268 & 1651.03 & 28.23 & 0.0250 & 1648.09 & 24.73 & 0.0216 \\
19 & 1674.49 & 30.37 & 0.0267 & 1674.49 & 28.62 & 0.0248 & 1671.55 & 24.93 & 0.0215 \\
20 & 1659.82 & 31.54 & 0.0267 & 1665.69 & 29.40 & 0.0248 & 1662.76 & 25.51 & 0.0214 \\
\hline
\end{tabular}

\begin{tabular}{rrrrrrrrrrr} 
& \multicolumn{4}{c}{$\psi_{j}=0, \theta=0.35$} & \multicolumn{3}{c}{$\psi_{j}=0.25, \theta=0.35$} & \multicolumn{2}{c}{$\psi_{j}=0.75, \theta=0.35$} \\
\hline$t$ & \multicolumn{1}{c}{$K_{i}$} & \multicolumn{1}{c}{$A_{i}$} & \multicolumn{1}{c}{$Z_{i}$} & \multicolumn{1}{c}{$K_{i}$} & \multicolumn{1}{c}{$A_{i}$} & $Z_{i}$ & $K_{i}$ & $A_{i}$ & \multicolumn{1}{c}{$Z_{i}$} \\
\hline 0 & 500.00 & 5.00 & 0.0492 & 500.00 & 5.00 & 0.0492 & 500.00 & 5.00 & 0.0492 \\
1 & 605.57 & 24.54 & 0.0552 & 607.04 & 23.76 & 0.0529 & 609.97 & 21.81 & 0.0479 \\
2 & 705.28 & 28.62 & 0.0565 & 706.74 & 27.26 & 0.0532 & 711.14 & 24.54 & 0.0469 \\
3 & 803.52 & 31.93 & 0.0561 & 804.99 & 30.18 & 0.0524 & 810.85 & 26.68 & 0.0456 \\
4 & 897.36 & 34.85 & 0.0556 & 898.83 & 32.71 & 0.0516 & 906.16 & 28.82 & 0.0444 \\
5 & 985.34 & 37.57 & 0.0550 & 988.27 & 35.04 & 0.0509 & 995.60 & 30.57 & 0.0433 \\
6 & 1067.45 & 39.91 & 0.0544 & 1071.85 & 37.18 & 0.0501 & 1079.18 & 32.12 & 0.0423 \\
7 & 1143.70 & 42.04 & 0.0539 & 1149.56 & 38.93 & 0.0494 & 1156.89 & 33.49 & 0.0414 \\
8 & 1214.08 & 43.99 & 0.0534 & 1221.41 & 40.68 & 0.0487 & 1228.74 & 34.65 & 0.0406 \\
9 & 1278.59 & 45.55 & 0.0530 & 1285.92 & 42.04 & 0.0481 & 1293.26 & 35.63 & 0.0399 \\
10 & 1338.71 & 47.10 & 0.0526 & 1344.57 & 43.41 & 0.0476 & 1353.37 & 36.60 & 0.0394 \\
11 & 1391.50 & 48.46 & 0.0522 & 1397.36 & 44.38 & 0.0472 & 1407.62 & 37.38 & 0.0388 \\
12 & 1439.88 & 49.83 & 0.0519 & 1444.28 & 45.55 & 0.0468 & 1456.01 & 38.15 & 0.0384 \\
13 & 1480.94 & 50.80 & 0.0516 & 1483.87 & 46.52 & 0.0465 & 1498.53 & 38.74 & 0.0380 \\
14 & 1519.06 & 51.77 & 0.0514 & 1521.99 & 47.30 & 0.0463 & 1536.66 & 39.32 & 0.0377 \\
15 & 1551.32 & 52.55 & 0.0511 & 1555.72 & 47.88 & 0.0460 & 1570.38 & 39.71 & 0.0373 \\
16 & 1580.65 & 53.33 & 0.0510 & 1585.04 & 48.46 & 0.0458 & 1601.17 & 40.29 & 0.0371 \\
17 & 1607.04 & 53.72 & 0.0508 & 1612.90 & 48.85 & 0.0457 & 1630.50 & 40.49 & 0.0368 \\
18 & 1630.50 & 54.11 & 0.0506 & 1637.83 & 49.44 & 0.0454 & 1655.43 & 40.88 & 0.0366 \\
19 & 1658.36 & 54.11 & 0.0502 & 1662.76 & 49.63 & 0.0452 & 1680.35 & 41.07 & 0.0364 \\
20 & 1652.49 & 56.63 & 0.0506 & 1653.96 & 51.58 & 0.0455 & 1670.09 & 42.43 & 0.0365 \\
\hline
\end{tabular}


Table IVb. Optimal Trajectories for Country $j\left(\psi_{i}=1.25\right)$

\begin{tabular}{|c|c|c|c|c|c|c|c|c|c|}
\hline \multirow[b]{2}{*}{$t$} & \multicolumn{3}{|c|}{$\psi_{j}=0, \theta=0.25$} & \multicolumn{3}{|c|}{$\psi_{j}=0.25, \theta=0.25$} & \multicolumn{3}{|c|}{$\psi_{j}=0.75, \theta=0.25$} \\
\hline & $K_{j}$ & $A_{j}$ & $Z_{j}$ & $K_{j}$ & $A_{j}$ & $Z_{j}$ & $K_{j}$ & $A_{j}$ & $Z_{j}$ \\
\hline 0 & 300.00 & 4.00 & 0.0598 & 300.00 & 4.00 & 0.0566 & 300.00 & 4.00 & 0.0506 \\
\hline 1 & 388.07 & 23.95 & 0.0807 & 389.74 & 21.04 & 0.0693 & 394.72 & 15.98 & 0.0513 \\
\hline 2 & 477.81 & 29.40 & 0.0827 & 481.13 & 25.32 & 0.0696 & 489.44 & 18.51 & 0.0489 \\
\hline 3 & 569.21 & 34.85 & 0.0847 & 574.19 & 29.60 & 0.0697 & 585.83 & 21.04 & 0.0471 \\
\hline 4 & 658.94 & 40.29 & 0.0861 & 665.59 & 33.87 & 0.0698 & 682.21 & 23.18 & 0.0455 \\
\hline 5 & 745.36 & 45.55 & 0.0874 & 753.67 & 37.77 & 0.0698 & 775.27 & 25.32 & 0.0441 \\
\hline 6 & 828.45 & 50.60 & 0.0885 & 838.42 & 41.46 & 0.0698 & 866.67 & 27.07 & 0.0429 \\
\hline 7 & 906.55 & 55.27 & 0.0894 & 918.18 & 44.77 & 0.0697 & 953.08 & 28.82 & 0.0419 \\
\hline 8 & 979.67 & 59.55 & 0.0901 & 992.96 & 48.08 & 0.0696 & 1032.84 & 30.37 & 0.0409 \\
\hline 9 & 1046.14 & 63.64 & 0.0909 & 1061.09 & 50.99 & 0.0696 & 1109.29 & 31.74 & 0.0402 \\
\hline 10 & 1107.62 & 67.33 & 0.0914 & 1124.24 & 53.52 & 0.0695 & 1177.42 & 32.90 & 0.0394 \\
\hline 11 & 1164.13 & 70.64 & 0.0919 & 1180.74 & 55.86 & 0.0694 & 1238.91 & 34.07 & 0.0389 \\
\hline 12 & 1215.64 & 73.75 & 0.0924 & 1232.26 & 58.00 & 0.0693 & 1297.07 & 34.85 & 0.0383 \\
\hline 13 & 1260.51 & 76.48 & 0.0928 & 1278.79 & 59.94 & 0.0692 & 1350.24 & 35.63 & 0.0379 \\
\hline 14 & 1300.39 & 78.81 & 0.0931 & 1320.33 & 61.50 & 0.0692 & 1396.77 & 36.40 & 0.0375 \\
\hline 15 & 1335.29 & 80.95 & 0.0933 & 1356.89 & 63.05 & 0.0692 & 1438.32 & 37.18 & 0.0372 \\
\hline 16 & 1365.20 & 82.90 & 0.0936 & 1388.47 & 64.42 & 0.0690 & 1478.20 & 37.77 & 0.0369 \\
\hline 17 & 1390.13 & 84.45 & 0.0938 & 1416.72 & 65.58 & 0.0690 & 1516.42 & 38.15 & 0.0366 \\
\hline 18 & 1415.05 & 85.81 & 0.0939 & 1443.30 & 66.36 & 0.0689 & 1548.00 & 38.54 & 0.0363 \\
\hline 19 & 1439.98 & 86.59 & 0.0939 & 1468.23 & 67.33 & 0.0690 & 1579.57 & 39.32 & 0.0361 \\
\hline \multirow[t]{2}{*}{20} & 1464.91 & 90.09 & 0.0948 & 1486.51 & 69.86 & 0.0693 & 1584.56 & 40.29 & 0.0361 \\
\hline & \multicolumn{3}{|c|}{$\psi_{j}=0, \theta=0.35$} & \multicolumn{3}{|c|}{$\psi_{j}=0.25, \theta=0.35$} & \multicolumn{3}{|c|}{$\psi_{j}=0.75, \theta=0.35$} \\
\hline$t$ & $K_{j}$ & $A_{j}$ & $Z_{j}$ & $K_{j}$ & $A_{j}$ & $Z_{j}$ & $K_{j}$ & $A_{j}$ & $Z_{j}$ \\
\hline 0 & 300.00 & 4.00 & 0.0703 & 300.00 & 4.00 & 0.0664 & 300.00 & 4.00 & 0.0594 \\
\hline 1 & 384.75 & 33.49 & 0.1226 & 386.41 & 29.79 & 0.1052 & 389.74 & 22.79 & 0.0768 \\
\hline 2 & 474.49 & 42.24 & 0.1294 & 476.15 & 36.79 & 0.1082 & 482.80 & 27.07 & 0.0752 \\
\hline 3 & 565.88 & 50.80 & 0.1344 & 567.55 & 43.41 & 0.1102 & 577.52 & 30.96 & 0.0733 \\
\hline 4 & 655.62 & 59.36 & 0.1386 & 657.28 & 50.02 & 0.1116 & 672.24 & 34.65 & 0.0718 \\
\hline 5 & 742.03 & 67.72 & 0.1423 & 743.70 & 56.44 & 0.1127 & 763.64 & 38.15 & 0.0702 \\
\hline 6 & 826.78 & 75.31 & 0.1454 & 826.78 & 62.28 & 0.1137 & 851.71 & 41.07 & 0.0687 \\
\hline 7 & 906.55 & 82.90 & 0.1480 & 904.89 & 67.72 & 0.1143 & 936.46 & 43.80 & 0.0675 \\
\hline 8 & 981.33 & 90.09 & 0.1504 & 978.01 & 72.78 & 0.1150 & 1014.57 & 46.32 & 0.0663 \\
\hline 9 & 1051.12 & 96.51 & 0.1522 & 1046.14 & 77.45 & 0.1154 & 1089.35 & 48.66 & 0.0653 \\
\hline 10 & 1115.93 & 102.74 & 0.1540 & 1109.29 & 81.73 & 0.1159 & 1157.48 & 50.80 & 0.0644 \\
\hline 11 & 1174.10 & 108.38 & 0.1556 & 1167.45 & 85.62 & 0.1160 & 1218.96 & 52.55 & 0.0636 \\
\hline 12 & 1223.95 & 113.44 & 0.1571 & 1220.63 & 89.12 & 0.1164 & 1275.46 & 54.30 & 0.0630 \\
\hline 13 & 1272.14 & 118.10 & 0.1582 & 1270.48 & 92.43 & 0.1167 & 1325.32 & 55.66 & 0.0623 \\
\hline 14 & 1315.35 & 122.00 & 0.1592 & 1312.02 & 95.54 & 0.1169 & 1371.85 & 57.02 & 0.0619 \\
\hline 15 & 1351.91 & 125.50 & 0.1601 & 1348.58 & 97.87 & 0.1169 & 1413.39 & 58.00 & 0.0613 \\
\hline 16 & 1383.48 & 128.80 & 0.1609 & 1383.48 & 100.21 & 0.1171 & 1448.29 & 59.16 & 0.0610 \\
\hline 17 & 1411.73 & 131.53 & 0.1613 & 1411.73 & 102.35 & 0.1171 & 1479.86 & 59.94 & 0.0606 \\
\hline 18 & 1438.32 & 134.06 & 0.1617 & 1438.32 & 103.90 & 0.1173 & 1509.78 & 60.52 & 0.0604 \\
\hline 19 & 1461.58 & 134.06 & 0.1617 & 1463.25 & 105.46 & 0.1172 & 1538.03 & 61.30 & 0.0601 \\
\hline 20 & 1479.86 & 141.45 & 0.1643 & 1481.52 & 109.93 & 0.1185 & 1548.00 & 63.44 & 0.0604 \\
\hline
\end{tabular}




\section{References}

Babusenko, Sergey, 1996. 'Russian-Turkish Relations Assessed: New Conditions and Contributing to Rapprochement', Nezavisimiya Gazete, in FBIS-SOV-96125-5, 27 June.

Barbieri, Katherine, 1996. 'Economic Interdependence: A Path to Peace or a Source of Interstate Conflict?', Journal of Peace Research 33(1): 29-50.

Başar, Tamer \& Geert Jan Oldser, 1982. Dynamic Noncooperative Game Theory. New York: Academic Press.

Brito, Dagobert L., 1972. 'A Dynamic Model of an Armaments Race', International Economic Review 13(2): 359-375.

Cappelen, Ådne; Nils P. Gleditsch \& Olav Bjerkholt, 1992. 'Guns, Butter, and Growth: The Case of Norway', in Steve Chan \& Alex Mintz, eds, Defense, Welfare and Growth. London: Routledge (61-80).

Deger, Saadet \& Somnath Sen, 1983. 'Military Expenditure Spin-off and Economic Development', Journal of Development Economics 13(1-2): 67-83.

Deger, Saadet \& Ron Smith, 1983. 'Military Expenditure and Growth in Less Developed Countries', Journal of Conflict Resolution 27(2): 335-353.

Faini, Ricardo; Patricia Annez \& Lance Taylor, 1984. 'Defense Spending, Economic Structure and Growth: Evidence Among Countries Over Time', Economic Development and Cultural Change 32(3): 487-498.

Garfinkel, Michelle R., 1990. 'Arming as a Strategic Investment in a Cooperative Equilibrium', American Economic Review 80(1): 50-68.

Gasiorowski, Mark \& Solomon W. Polachek, 1982. 'Conflict and Interdependence', Journal of Conflict Resolution 26(4): 709-729.

Goldberg, David E., 1989. Genetic Algorithms in Search Optimization and Machine Learning. Reading, MA: Addison Wesley.

Grefensttete, John J., 1986. 'Optimization of Control Parameters for Genetic Algorithms', IEEE Transactions on Systems, Man and Cybernetics SMC16: 122-128.

Heo, Uk, 1998. 'Modeling the Defense-Growth Relationship Around the Globe', Journal of Conflict Resolution 42(5): 637-657.
Hirschman, Albert O., 1980. National Power and the Structure of Foreign Trade. Berkeley, CA: University of California Press.

Holland, John H., 1975. Adaptation in Natural and Artificial Systems. Ann Arbor, MI: University of Michigan Press.

Intriligator, Michael, 1975. 'Strategic Considerations in the Richardson Model of Arms Race', Journal of Political Economy 83(2): 43-62.

Kuznets, Simon, 1980. 'Driving Forces of Economic Growth', Weltwirtschaftliches Archiv 116(3): 409-431.

Levine, Paul \& Ron Smith, 1997. 'The Arms Trade and the Stability of Regional Arms Races', Journal of Economic Dynamics and Control 21(2-3): 631-654.

Liberman, Peter, 1996. 'Trading with the Enemy: Security and Relative Economic Gains', International Security 21(1): 147-175.

Mercenier, Jean \& Philippe Michel, 1994. 'Discrete-time Finite Horizon Approximation of Infinite Horizon Optimization Problems with Steady-State Invariance', Econometrica 62(3): 635-656.

Michalewicz, Zbigniew, 1992. Genetic Algorithm + Data Structure $=$ Evolution Program. Berlin: Springer-Verlag.

Mintz, Alex \& Chi Huang, 1990. 'Defense Expenditures, Economic Growth and the "Peace Dividend": A Longitudinal Analysis of 103 Countries', Journal of Conflict Resolution 39(2): 283-305.

Mintz, Alex \& Chi Huang, 1991. 'Guns versus Butter: The Indirect Link', American Journal of Political Science 35(3): 738-757.

Özyıldırım, Süheyla, 1997. 'Computing Openloop Noncooperative Solution in Discrete Dynamic Games', Journal of Evolutionary Economics 7(1): 23-40.

Oneal, John R. \& Bruce Russett, 1999. 'Assessing the Liberal Peace with Alternative Specifications: Trade Still Reduces Conflict', Journal of Peace Research 36(4): 423-442.

Polachek, Solomon W., 1980. 'Conflict and Trade', Journal of Conflict Resolution 24(1): 55-78.

Polachek, Solomon W.; John Robst \& Yuan-Ching Chang, 1999. 'Liberalism and Interdependence: Extending the Trade-Conflict Model', Journal of Peace Research 36(4): 404-422. 
Pollins, Brian M., 1989. 'Conflict, Cooperation, and Commerce: The Effect of International Political Interactions on Bilateral Trade Flows', American Journal of Political Science 33(3): 737-761.

Reuveny, Rafael \& Heejoon Kang, 1998. 'Bilateral Trade and Political Conflict/Cooperation: Do Goods Matter?', Journal of Peace Research 35(5): 581-602.

Richardson, Lewis F., 1960. Arms and Insecurity. Chicago, IL: Boxwood Press.

Simaan, M. \& J. B. Cruz, 1975. 'Formulation of Richardson's Model of Arms Race from a Differential Game Viewpoint', Review of Economic Studies 42(1): 67-77.

Smoker, Paul, 1989. 'Artificial Intelligence Models of Arms Race', in Nils Petter Gleditsch \& Olav Njølstad, eds, Arms Races: Technological and Political Dynamics. London: Sage (78-86).

van der Ploeg, Frederick \& Aart J. de Zeeuw, 1990. 'Perfect Equilibrium in a Model of Competitive Arms Accumulation', International Economic Review 31(1): 131-146.
Walt, Stephen M., 1999. 'Rigor and Rigor Mortis? Rational Choice and Security Studies', International Security 23(4): 5-48.

Ward, Michael \& David Davis, 1992. 'Sizing up the Peace Dividend: Economic Growth and Military Spending in the United States, 1948-1996', American Political Science Review 86(3): 748-755.

SÜHEYLA ÖZYILDIRIM, b. 1965, PhD in Economics (Bilkent University, 1997); Assistant Professor, Bilkent University (1998-). Current research interests: dynamic games, international trade and international externalities.

NUR BİLGE CRISS, b. 1949, PhD in History (George Washington University, 1990); Assistant Professor, Bilkent University (1990- ). Current research interests: Turkish-Russian relations, national identity formation. 